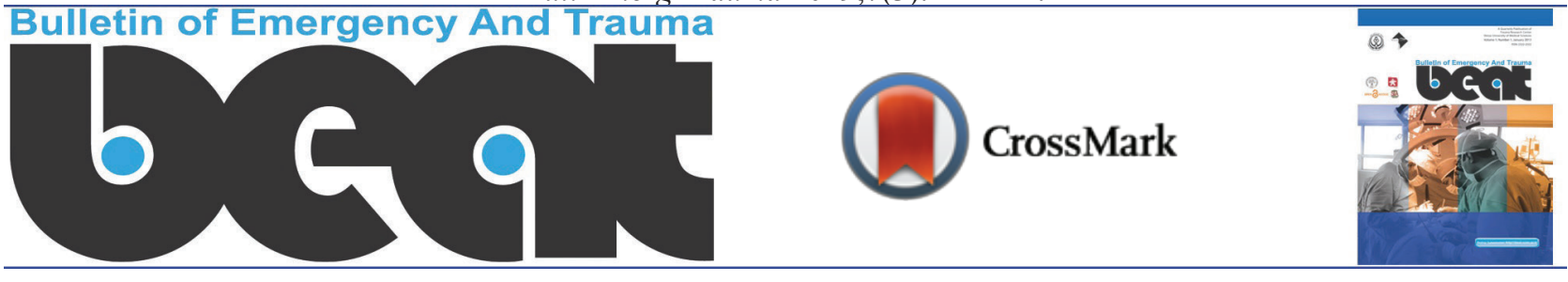

\title{
Comparative Study of Stewardship of Road Traffic Injuries Prevention with a Focus on the Role of Health System; Three Pioneer Countries and Three Similar to Iran
}

\author{
Saber Azami-Aghdash', Homayoun Sadeghi-Bazarghani², Ramin Rezapour ${ }^{3}$, Mahdiyeh Heydarï $^{2}$, Naser $^{2}$ \\ Derakhshani $^{4^{*}}$
}

\begin{abstract}
${ }^{1}$ Tabriz Health Services Management Research Center, Health Management and Safety Promotion Research Institute, Tabriz University of Medical Sciences, Tabriz, Iran

${ }^{2}$ Road Traffic Injury Research Center, Tabriz University of Medical Sciences, Tabriz, Iran

${ }^{3}$ Department of Health Services Management, Iranian Center of Excellence in Health Management, Tabriz University of Medical Sciences, Tabriz, Iran

${ }^{4}$ Health Management and Economics Research Center, Iran University of Medical Sciences, Tehran, Iran
\end{abstract}

*Corresponding author: Naser Derakhshani

Address: Health Management and Economics Research Center, Iran University of

Medical Sciences, Tehran, Iran. Tel: +98-914-1078750,

e-mail: derakhshani.mhc@gmail.com
Received: December 8, 2018

Revised: May 16, 2019

Accepted: May 31, 2019

\section{ABSTRACT}

Objective: To compare the stewardship of road traffic accidents (RTIs) prevention in three pioneer countries and three similar ones to Iran.

Methods: In this descriptive comparative study, the United States of America, Sweden, and Brazil as the pioneer countries in RTIs prevention were compared to the India, Pakistan, and Turkey as the countries socioeconomically similar to Iran. Embase, PubMed, Scopus, IranDoc, IranMedex, SID, and MagIran were searched. Also a hand search conducted on websites and search engines using related keywords.

Results: In the pioneer countries in RTIs prevention there was a delegation to a particular organization. In the other three countries a part of the Ministry of Transportation had the overall responsibility of RTIs. In Iran there was uncertainty in the stewardship of RTIs prevention. There was little evidence on the role and activities of health systems in RTIs prevention.

Conclusion: It seems necessary to define a lead agency organization on RTIs prevention in Iran with sufficient authority and resources. This study also recommends conducting reliable studies to investigate the possible roles that the health system of a country can assume regarding the RTIs prevention.

Keywords: Road traffic accident; Road traffic injury; Traffic-collision injuries; Policy; Stewardship; Decision making.

Please cite this paper as:

Azami-Aghdash S, Sadeghi-Bazarghani H, Rezapour R, Heydari M, Derakhshani N. Comparative Study of Stewardship of Road Traffic Injuries Prevention with a Focus on the Role of Health System; Three Pioneer Countries and Three Similar to Iran. Bull Emerg Trauma. 2019;7(3):212-222. doi: 10.29252/beat-070302. 


\section{Introduction}

$\mathrm{T}$ oday one of the major causes of mortality and morbidity around the world, especially in Low and Middle Income Countries(LMICs), is the Road Traffic Injuries (RTIs) [1, 2]. Moreover, the RTIs make huge and catastrophic direct and indirect costs to the individuals and the governments [3]. It is estimated that the global RTIs is about $\$ 518,000$ billion each year, of which $\$ 65,000$ billion is a share of LMICs $[4,5]$. It is estimated that 1.2 million people die and 50 million people get injured in the traffic accidents annually [6]. It is estimated that this numbers will increase in the future 20 years by $65 \%$ [4]. The estimates shows that for every death due to the RTIs, 16 people get hospitalized and 400 people need outpatient hospital services or experience transient activity limit [7] so that the majority of hospital emergency department visitors are victims of the RTIs [3]. The mortality and morbidity due to the RTIs are a public health problem in LMICs [8]. In addition, attempts to prevention of RTIs in the LMICs has been hampered by restrictions such as lack of adequate knowledge and lack of reliable statistics RTIs [9].

The high income countries (HIC) have developed some regulations to decrease the RTIs including: speed limit, compulsory use of helmet and seat belt, alcohol ban, and safer design of the vehicles $[10,11]$. For the prevention of the RTIs we need a comprehensive integration of the interventions [1214]. Most countries that have achieved considerable success in reducing the RTIs, benefit from a strong controlling institute/organization that has sufficient authority to plan the actions and then the other involved organizations cooperate with it $[15,16]$. Also, given the many interventions in the area of RTIs conducted, but still puts a lot of economic burden and mortality on the countries [17]. About the burden of RTIs on the health systems, the health systems have an active role in policy making and prevention of the RTIs around the world [18]. Also, the World Health Organization (WHO) illustrate which RTIs is a major public health and developing crisis $[4,19]$. Considering the clear role of the health system in post-crash (after accidents), the role of health system in prevention or pre-crash (before the accident) is not clear. Also health system research in this field mostly focused on clinical subject such as harm reduction [20]. Thus it is necessary to investigate the role of the health system in prevention of RTIs. This study conducted with the aim of comparing and description the lead agencies that are responsible for the RTIs prevention with a focus on the role of health system (all actors inside the governmental section that are engagement in health service provision) in three pioneer countries and three similar ones to Iran.

\section{Materials and Methods}

\section{Search Strategy}

The needed document for this descriptive comparative study gathered from the databases of EMBASE, PubMed, Scopus, IranDoc, IranMedex, MagIran, and SID and the websites of the World Health Organization (WHO), the United Nations (UN), the World Bank, Ministries of Roads and Transportation (or the corresponding Ministries in the studied countries), Traffic Police, Legal/Forensic Medicine, Ministry of Health, and the search engines of Yahoo and Google. Some of the relevant journals were searched manually. Reference lists of the selected articles also were checked. Finally, we also searched the gray literature and did expert contact. In order to check the grey literature, the European Association for Grey Literature Exploitation (EAGLE) and the Healthcare Management Information Consortium (HMIC), ProQuest and IranDoc databases were searched. The literature search was done up to September 31 August 2018 (Table 1).

\section{Eligibility Criteria}

Eligibility criteria for inclusion of documents were documents on the RTIs area (not airway, railroad or other transport form), documents that discuses about stewardship in RTIs area, documents that publish in selected counties and documents published in Persian and English language. Among 2917 retrieved documents in databases and other resources, 1116 documents were excluded due to the duplicated between deferent sources. In reviewing the titles and abstracts, 1721 documents were removed. In review of the full text 50 documents were excluded, and finally 30 documents were included (Figure 1).

Table 1. Complete search strategy for PubMed databases

\begin{tabular}{|c|c|c|}
\hline Set & Strategy & Results \\
\hline$\# 1$ & $\begin{array}{l}((((((((\text { road[Title]) OR traffic[Title]) OR injury[Title]) OR accident[Title]) OR crash[Title]) OR } \\
\text { collision[Title]) OR Motor Vehicles[Title]) OR motorcycle[Title]) OR pedestrians[Title]) OR car[Title]) } \\
\text { OR automobile[Title] }\end{array}$ & 79379 \\
\hline$\# 2$ & $\begin{array}{l}(((((()(\text { lead agencies[Title/Abstract]) OR management[Title/Abstract]) OR policy making[Title/ } \\
\text { Abstract]) OR decision making[Title/Abstract]) OR legislation[Title/Abstract]) OR stewardship[Title/ } \\
\text { Abstract]) OR leadership[Title/Abstract]) OR governance) OR responsibility) OR authority }\end{array}$ & 538052 \\
\hline$\# 3$ & $\begin{array}{l}((((((\text { United States of America[Affiliation]) OR Sweden[Affiliation]) OR Brazil[Affiliation]) OR } \\
\text { Turkey[Affiliation]) OR India[Affiliation]) OR Pakistan[Affiliation]) OR Iran[Affiliation] }\end{array}$ & 534195 \\
\hline \#4 & $\# 1$ AND \#2 AND \#3 & $516^{\mathrm{a}}$ \\
\hline
\end{tabular}

${ }^{a}$ Filters activated: Full text, Publication date from 2000/01/01 to 2018/08/31, Humans, English 

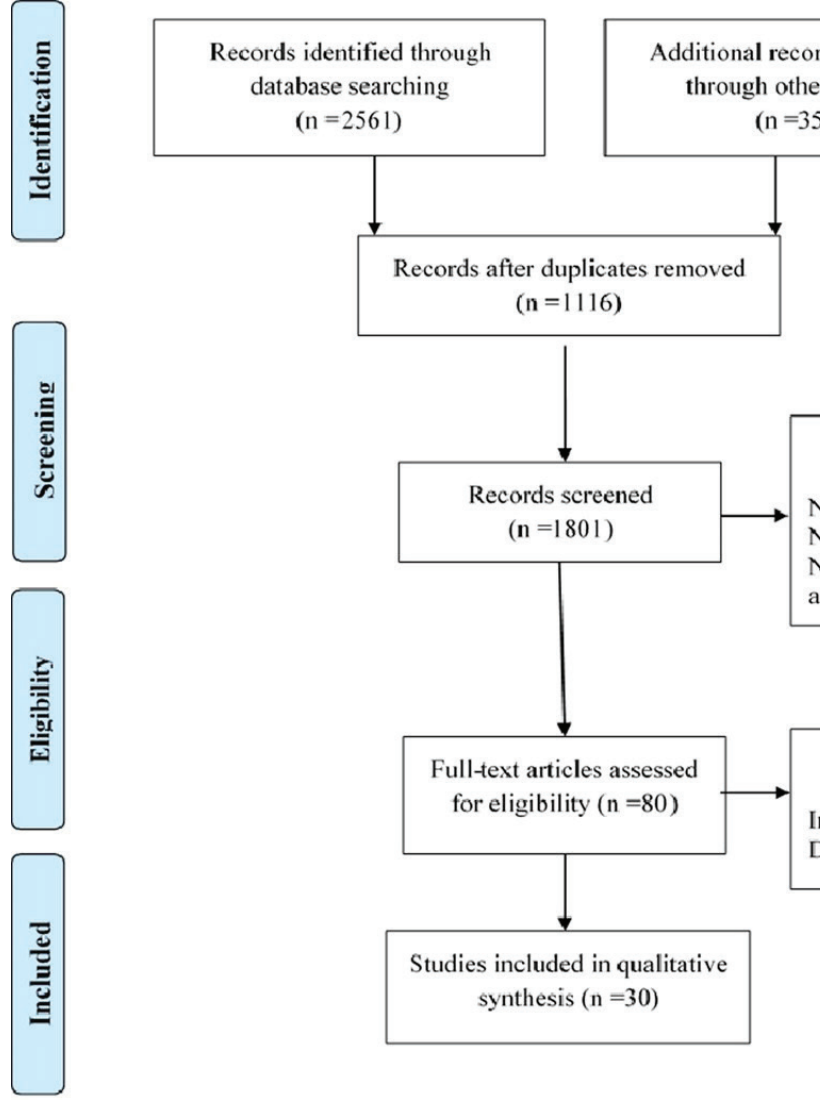

$$
(\mathrm{n}=1116)
$$

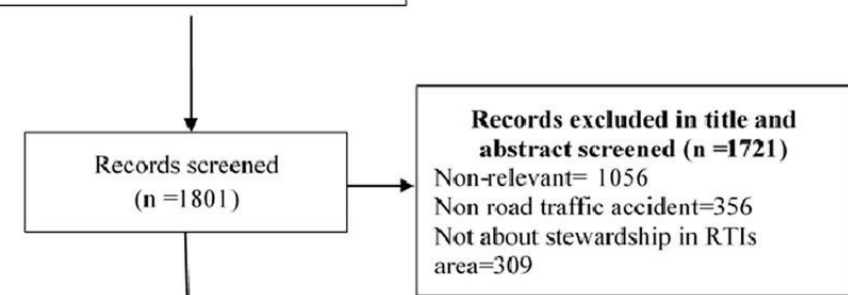

Studies included in qualitative synthesis $(\mathrm{n}=30)$

Fig. 1. Flow diagram of the search and inclusion process.

\section{Countries Selection}

All available articles and reports on the RTIs policy making in the USA, Sweden, Brazil (as the pioneer countries in RTIs prevention), and Turkey, India, Pakistan (as the countries similar to Iran), and the Iran were reviewed. The reason for selection of pioneer countries was their successful experiences in reducing the RTIs and for the other three countries was their similarity to Iran in social, economic and the RTIs situation. The WHO report 2015 on the burden of RTIs was used as the basis for selection of countries. The other criterion for selection was the availability of data in English language. So, countries such as Germany, Italy and some other European countries that the evidence about their RTIs prevention was not mainly in English were not selected. The three countries were selected among 56 countries. The countries similar to Iran were selected by the availability of evidence in English language and the similarities in cultural, social, economic, population, number of vehicles (India was an exception in number of vehicles), and traffic policies and regulations situation. The three countries were selected out of 21 countries.

\section{Data Extraction and Data Analysis}

The study tool was a comparative form that included the country name and information of transportation, the policy making institute(s), executive bodies, evaluating institute(s), the role of health system in
RTIs prevention, and examples of policies related to the health system. The text data were analyzed manually in an interpretive manner and by using the Descriptive Content-Analysis method. The ContentAnalysis was applied which is a common method for identifying and reporting the patterns within the texts [21-24].

\section{Results}

The information of the three pioneer countries in RTIs prevention, three socio-economically similar to Iran, and the Iran about the RTIs prevention policy making and the role of health system in that are presented in Table 2 .

\section{Iran}

The general responsibility of transportation in Iran is on the Ministry of Roads and Urban Development. The Ministry was set up in May 2011 by merging the two former Ministry of Roads and Transportation and the Ministry of Housing and Urban Development. The Ministry has 6 deputies: Planning and economy of transportation, urban development and architecture, Housing and construction, rural roads, Management and resources development, and the budget, legal, and parliament affairs [25]. Several organizations are involved in road transportation in Iran. One most important of them is the Road Maintenance and Transportation Organization which is part of 


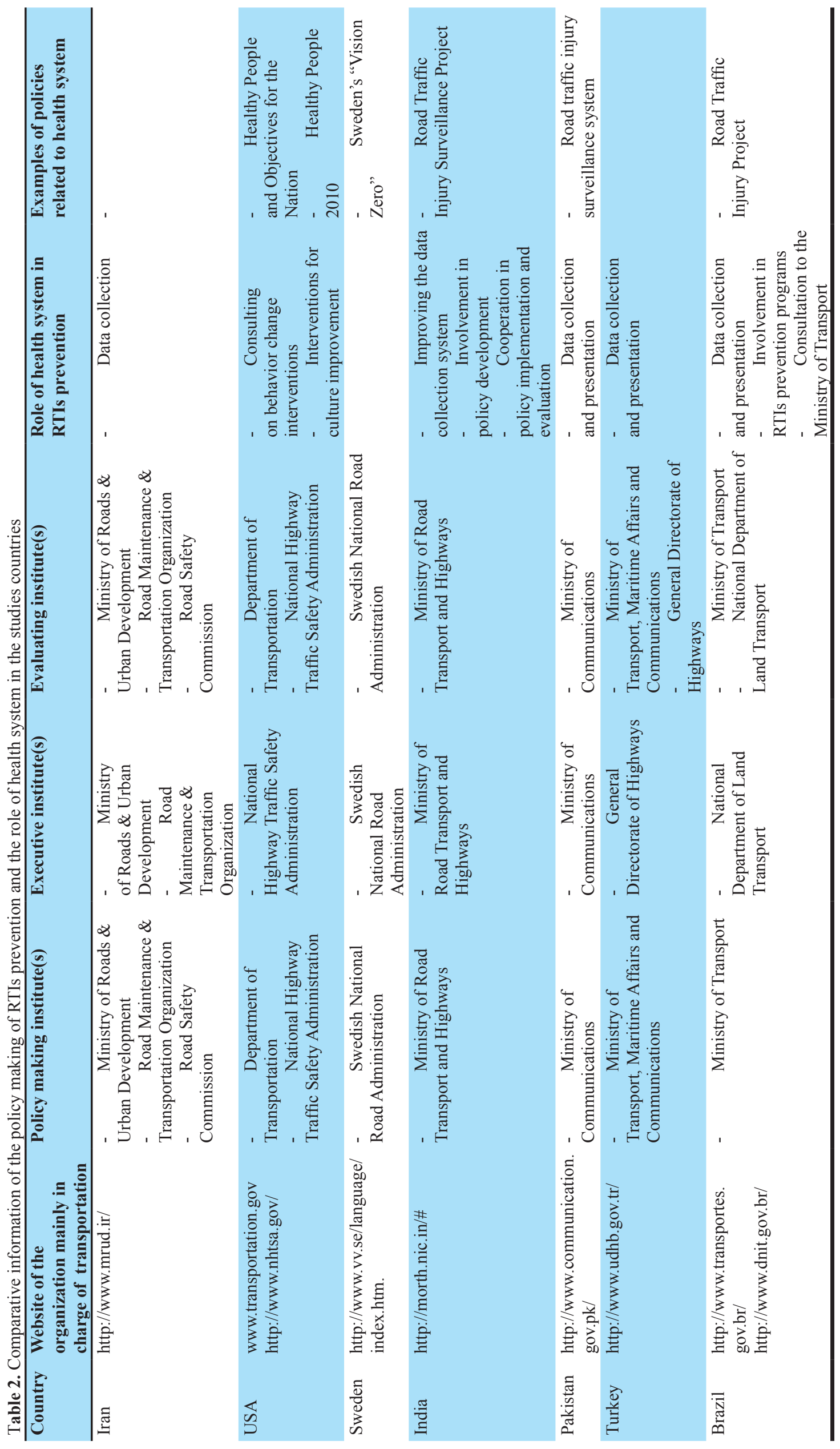


the Ministry of Roads and Urban Development. The Organization has four deputies including: Road maintenance, Transportation, Planning, and the Management and resources development. The organization has six main duties which are listed here according to their order:

- Road maintenance: making the roads better and safer

- Road transportation: preparing the regulations on national and international transportation, building, operating, developing and maintaining the public terminals of passenger and cargo, licensing and supervising the passenger and cargo companies.

- Improvement of safety of and management of the traffic in the roads: defining the standards of vehicle, preparing the regulations of safety, analyzing the road crashes and deaths, planning and implementing safe roads plans.

- Development of international transportation: road transportation and building the border terminals

- Intelligent transportation systems: planning, designing, monitoring and utilizing the online surveillance and data collection systems.

- Traffic management and accidents communication: communicating and informing the people to choose the path [26].

The Cabinet of Ministers in 2003 approved the constitution of the Road Safety Commission with the aim of improving the safety level of the transportation and reducing the RTIs [27]. Reviewing the duties of the Commission we noticed a considerable overlap in the duties of the Road Maintenance and Transportation Organization. Also there is an overlap between these two bodies and the Traffic Police in terms of duties. through Administrative High Council ratification number 1901/74022 dated 2003/6/13 all duties, workforce, equipment's, obligations and credits of maintenance deputy of "Road and Transport Ministry " was transferred to state terminals and transport organization and the aforesaid deputy was omitted and according to the mentioned ratification paragraph (5), duties and directing affairs of "State Transport High Council Secretariat " was separated from organization and transferred to "Road and Transport Ministry " and the name of the organization changed to " Road Maintenance and Transport Organization ". Road Maintenance and Transport Organization as a custodian of maintaining, improving and securing the country's roads has a special impact on national development and increasing the country's economic productivity. Some of the tasks of the Road Maintenance and Transport Organization are: Set policies, road maintenance planning and policies and establishing national coordination for their implementation, preparation and delivery of technical and administrative instructions for maintenance of roads, technical buildings and related buildings to road, to construct and Interest to develop and maintain the buildings and facilities needed for optimal use of the road and providing convenient road services.

The health system in Iran had no significant activity on reducing the RTIs in recent years. Its main role is after the accidents happen and is limited to the prehospital and hospital emergency services. Recently the Disaster and Emergency Medical Management Center has been set up in the Ministry of Health and Medical Education and all the provinces. These centers were still not seriously involved in the prevention of traffic accidents due to their newness and lack of sufficient authority and resources. Maybe the only activity that the health system is involved in regarding the RTIs is the collecting data on the injuries and deaths due to RTIs. Yet, this activity is not performed perfectly and in a systematic manner.

\section{The USA}

In the USA, the general policies of transportation (railways, airways, sailing, and roads) are developed by the Department of Transportation. And the National Highway Traffic Safety Administration works particularly on the roads. The Administration is part of the Department of Transportation and is established in 1970. Its mission is to reduce the deaths, injuries and the costs of traffic accidents. The Administration plays its role by developing the safety standards of the vehicles, developing the regulations, providing financial and consultation help for local governments, and conducting research on road safety [28].

Although some administrations of the Department of Transportation- such as Roads and Bridges, Public Transit, National Highway Traffic Safety Administration (NHTSA)- are involved in road transportation, but the main executive responsibility in safety and reducing the RTIs is upon the National Highway Traffic Safety Administration. In the field of control and assessment of prevention and road safety activities, both the Department of Transportation and the National Highway Traffic Safety Administration work by their own regulations and processes $[29,30]$. Although the role of health system in the USA in RTIs prevention is not clearly defined, but we can count the following roles for it according to the reports and articles [31]:

- Consultation: such as consultations on Pasteurization of the milk, water Chlorination, avoiding high-fat and salty foods, regular exercising and so on.

- Behavior interventions: such as improving the lifestyle and behavior changes on quitting the smoke, cardiovascular diseases prevention, cancer prevention and so on.

- Culture interventions: such as education through the media about the seatbelt and the obvious examples of the role in RTIs prevention are the "Healthy people, Objectives for nation" and "Healthy people 2010" which are developed by the Department of Health and Human Services (Table 3) [32, 33]. 
Table 3. The objectives of the US "Healthy people 2010" that are related to RTIs

\begin{tabular}{|c|c|c|c|}
\hline $\begin{array}{l}\text { Number of } \\
\text { objective }\end{array}$ & Title of objective & Base situation & Desired situation \\
\hline $15-15$ & Deaths from motor vehicle crashes & 15.6 deaths per 100,000 people & 9.2 deaths per 100,000 people \\
\hline $15-16$ & Pedestrian deaths on public roads & 1.9 deaths per 100,000 people & 1 death per 100,000 people \\
\hline $15-17$ & $\begin{array}{l}\text { Nonfatal motor vehicle crash-related } \\
\text { injuries on public roads }\end{array}$ & 1181 injuries per 100,000 people & 933 injuries per 100,000 people \\
\hline $15-18$ & $\begin{array}{l}\text { Nonfatal pedestrian injuries on public } \\
\text { roads }\end{array}$ & 26 injuries per 100,000 people & 19 injuries per 100,000 people \\
\hline $15-19$ & Safety belt use & $69 \%$ of total population & $92 \%$ of total population \\
\hline $15-20$ & Child restraint use & $92 \%$ of children $\leq 4$ years old & $100 \%$ of children $\leq 4$ years old \\
\hline $15-21$ & Motorcycle helmet use & $67 \%$ of motorcyclists & $79 \%$ of motorcyclists \\
\hline
\end{tabular}

\section{Sweden}

In the late 1960s the Swedish Road Safety Office (SRSO) was set up with the aim of assuring the safety of the roads. Although the SRSO had not sufficient power and resources for reducing the burden of RTIs, but the country had experienced a decreasing trend of RTIs mortality during 1970 s to 1980 s. In 1993 the SRSO merged with a larger and more powerful organization named the Swedish National Roads Administration. Then the administration became responsible for the overall policy making, implementing, monitoring and surveillance of the plans, safety of the roads, maintenance of the roads, and all works on road transportation on behalf of the Ministry of Transportation and Communication28] ].

The Swedish National Roads Administration includes the Chairman, 7 local offices, 2 support and development centers (society and traffic, information and management), 2 collaborate organizations (agency for traffic crashes record, agency for driving license test), 4 commercial units (traffic operation, consultation services, construction and maintenance services, education and development services) [34].

The mast famous policy in Sweden for reduction of the RTIs that is related to the health system is the "Vision Zero". This policy was passed by the Parliament in 1997 with the aim of creating a road traffic system without any fatalities and serious crashes $[35,36]$. The public health introduced as the basic introduction of the policy. The fundamental principle of the Vision was that "Life and health can never be exchanged for other benefits within the society". The principle changed the conventional method of assuming monetary value for health and life of the people and then the cost-benefit analysis were done for decisions about investments on road infrastructures [37]. The results of implementing the Vision Zero were impressive. So that despite the increased traffic, the mortality caused by the traffic crashes dropped from 541 in 1997 to 314 deaths in $2011[25,38]$.

\section{India}

The responsibility of developing the regulations and laws in India is with the Road Transportation and Highways Unit. Road transportation is of high importance in India because $60 \%$ of the cargo and $90 \%$ of the passengers are transported through the roads [39]. In the year 1999 the Ministry of Land Transportation divided to two units of sea transportation and roads and highway transportation. Then the situation became prepared to have a separate Ministry of Roads and Highway Transportation in the year 2000. The two Ministries of "Ministry of Shipping" and "Ministry of Road Transport and Highways" merged again to make the Ministry of Ministry of Shipping, Government. The roads and highway transportation now is one of the two main deputies of the Ministry [40]. The Deputy of Roads and Highway Transportation is running by a common secretary who is chosen by the Minister. It has a financial manager and also an operations manager to maintain and repair the roads. There is also a consultant for researches, data gathering and analysis [41]. The Deputy of Roads and Highway Transportation has 14 local administrations in various parts of the country [42].

Like many other sectors in India, in the road transportation sector the health system has an active and constructive role of which are providing pre-hospital, hospital and rehabilitation care, contribution in data collection, participation in policy development, cooperation in prevention programs, and having consultation role [43]. A good example of the role of health system of India in prevention of traffic accidents is the Road Traffic Injury Surveillance Project. The project was implemented by the Medical Research Council, World Health Organization, and the Indian Ministry of Health and Welfare in 2007 after the many defects in the data system of the health sector. The main objective of the project was to establish the care system in 25 large hospitals of the India which achieved great successes [44]. Then it merged with the Integrated Disease Surveillance Project [45].

\section{Pakistan}

The responsibility of policy making and management of road transportation in Pakistan is with the Ministry of Communications. It is one of the oldest Ministries of the Pakistan established in 1947 and includes 4 main subset organizations: The National Highway Organizations which constructs, repairs and maintains the roads and highways; The 
National Highways and Motorway Police which develops, implements, and observes the roads transportation regulations; The National Transport Research Centre which performs the research and development and provides the information for decision making and cost-effectiveness of the programs and policies; The Construction Machinery Training Institute which established in 1986 with the cooperation of Japan and achieved successes in research and building the transportation machines. Despite some other countries like India, there is not much evidence on the role of the health system in prevention of traffic accidents. It seems that activities of the health system on RTIs are mainly limited to care of the RTIs' injuries. In the year 2006 the health system of Pakistan designed and implemented the road traffic injury surveillance with the aim of estimating the burden of the traffic injuries, studying the hospitalized traffic injuries, and providing solutions for reduction of the traffic injuries. As a result of implementing this system, attention to the RTIs grew. The outputs of the system showed that the mortality and morbidity of the RTIs are higher than the statistics that the police had [46].

\section{Turkey}

The Ministry of Transport, Maritime and Communication had the responsibility of road transportation in Turkey. The Ministry is one of the oldest Ministries of its kind which established in 1939 and has had many changes since then. It has the responsibility of airway, sea, railway, and roads transportations. In the field of road transportations, the priorities are improving the roads infrastructure, developing the highways and freeways, assuring roads safety, and research and development of the road transportation. The road transportation unit of the Ministry established in 1950 and has 18 units around the country now [47]. Consequently, to the excessive changes in the health system of Turkey in recent years that improved the health status of the country, the health system became involved in many activities to identify and remove the risk factors of traffic injuries which have led to considerable reduction on RTIs [48]. So that according to the WHO (2015), the mortality due to RTIs has been declined from 7 to 5 deaths per every 100,000 populations between 2007 and 2013 [49]. Yet, we could not find any evidence that show the activities of the health system in this regard.

\section{Brazil}

The Ministry of Transport has the overall responsibility of transportation in Brazil. It is established in 1992 and is the main body for regulation and supervision in transportation. The road transportation unit within the Ministry specifically performs the tasks related to roads which mainly are executive and to some extent observatory. The Ministry of Health has a significant role about the RTIs of which are gathering and reporting data to the Ministry of Transport, involvement in some projects of the Ministry of Transport, and providing consultations. Two major activities of the Ministry of Health of Brazil are presented here as examples [37]:

\section{Documenting the Road Traffic Injuries}

Injuries -mainly by violence and RTIs- are the second most common causes of death in Brazil after the cardiovascular diseases. A study based on death registry system of the Ministry of Health for the period of 1991 to 2001 showed that the number of deaths due to RTIs has grown considerably between 1991 and 1997. So that it had reached its peak in 1997 by 35756 deaths. Reporting this data to the Ministry of Transport resulted in passing new law that moved the responsibility of the traffic management to the local authorities and also proposed heavier punishments for the offending drivers.

\section{Defining the Priorities}

The Brazilian Policy for Reduction of Morbidity and Mortality by Accidents and Violence passed in 2001. Although the statistics showed that the mortality by suicide was more prevalent than the RTIs, the Ministry of Health decided to take later as its priority. Some indicators are compared between the studied countries according to the WHO report 2015 (Table 4). As it can be seen in Table 4, in the difference of country reported deaths and WHO estimation is big for Iran and the similar countries- except for Turkey. The share of RTIs' cost on GDP in Iran is much higher than the pioneer countries. It is also higher than Pakistan. All studied countries have separate national budget for prevention of RTIs, except for Pakistan. But in Iran there is no separate budget for this purpose and the involved organizations use part of their budget in this regard. All countries, except Pakistan, had national strategy for reducing RTIs. The attracting point about the planned annual rate of reduction was that the plans in the pioneer countries were long term but in Iran it was annual plan. The frontal impact standards, electronic stability control, and the pedestrian protection standards were not applied in Iran, India and Pakistan. But they were in practice in the pioneer countries and Turkey. Like the pioneer countries, Iran has an emergency room injury surveillance system. The speed limit law, drinking and driving law, helmet law, seat belt law, and mobile phone law were in practice in all studied countries. These laws in Iran were as highly effective as the pioneer countries, while they were less effective in the countries similar to Iran. The child restraint law was in practice only in pioneer countries and Turkey.

\section{Discussion}

Findings of the study showed that there is an uncertainty about the stewardship of RTIs' 
Table 4. Comparison of Iran with the selected countries (pioneers and similar) according to the WHO report 2015

\begin{tabular}{|c|c|c|c|c|c|c|c|}
\hline \multirow{2}{*}{$\begin{array}{l}\text { Country } \\
\text { Indicator } \\
\end{array}$} & \multirow[t]{2}{*}{ Iran } & \multicolumn{3}{|c|}{ Pioneer countries } & \multicolumn{3}{|c|}{ Countries similar to Iran } \\
\hline & & USA & Sweden & Brazil & Turkey & India & Pakistan \\
\hline $\begin{array}{l}\text { Number of deaths due to } \\
\text { traffic accidents (country } \\
\text { reported) }\end{array}$ & 17994 & 32719 & 260 & 42291 & 3685 & 137572 & 7636 \\
\hline $\begin{array}{l}\text { Number of deaths due to } \\
\text { traffic accidents (WHO } \\
\text { estimation) }\end{array}$ & 24896 & 34064 & 272 & 46935 & 6687 & 207551 & 25781 \\
\hline $\begin{array}{l}\text { Difference of country } \\
\text { reported death and WHO } \\
\text { estimation (\%) }\end{array}$ & $\begin{array}{l}6902 \\
((38.3)\end{array}$ & $\begin{array}{l}1345 \\
(4.1)\end{array}$ & $\begin{array}{l}12 \\
(4.6)\end{array}$ & $\begin{array}{l}4644 \\
(9.8)\end{array}$ & $\begin{array}{l}2 \\
(-)\end{array}$ & $\begin{array}{l}69979 \\
(50.8)\end{array}$ & $\begin{array}{l}18145 \\
(23.7)\end{array}$ \\
\hline Death per 100,000 population & 32.1 & 10.6 & 2.8 & 13.4 & 8.9 & 16.8 & 14.2 \\
\hline $\begin{array}{l}\text { Total number of registered } \\
\text { vehicles (car, motorcycle, } \\
\text { bike, ...) }\end{array}$ & 26886457 & 265043362 & 5755952 & 81600720 & 17939447 & 159490578 & 9080437 \\
\hline $\begin{array}{l}\text { Share of traffic accidents' cost } \\
\text { of GDP }\end{array}$ & 6 & 1.9 & Under \%1 & 1.2 & - & 3 & - \\
\hline $\begin{array}{l}\text { Financing through separate } \\
\text { national budget }\end{array}$ & $\mathrm{NO}$ & YES & YES & YES & YES & YES & NO \\
\hline $\begin{array}{l}\text { National strategy for traffic } \\
\text { accidents }\end{array}$ & YES & YES & YES & YES & YES & YES & NO \\
\hline $\begin{array}{l}\text { Planned annual rate of } \\
\text { reduction of traffic accident } \\
\text { deaths }\end{array}$ & $10 \%$ & $\begin{array}{l}1.05 \\
\text { people } \\
\text { per } 100 \\
\text { million } \\
\text { travel } \\
\text { miles }\end{array}$ & $\begin{array}{l}50 \% \text { from } \\
(2007-2020)\end{array}$ & $\begin{array}{l}\text { Reduce the } \\
\text { death rate } \\
\text { from \%18 to } \\
\% 112004- \\
2014\end{array}$ & $\begin{array}{l}50 \% \text { from } \\
(2012-2020)\end{array}$ & - & - \\
\hline $\begin{array}{l}\text { Applying frontal impact } \\
\text { standards }\end{array}$ & $\mathrm{NO}$ & YES & YES & YES & YES & NO & NO \\
\hline $\begin{array}{l}\text { Applying electronic stability } \\
\text { control }\end{array}$ & $\mathrm{NO}$ & YES & YES & $\mathrm{NO}$ & YES & NO & NO \\
\hline $\begin{array}{l}\text { Applying pedestrian } \\
\text { protection standards }\end{array}$ & $\mathrm{NO}$ & NO & YES & $\mathrm{NO}$ & YES & NO & $\mathrm{NO}$ \\
\hline $\begin{array}{l}\text { Emergency room injury } \\
\text { surveillance system }\end{array}$ & YES & YES & YES & YES & YES & NO & $\mathrm{NO}$ \\
\hline $\begin{array}{l}\text { Speed limit law and its } \\
\text { effectiveness score ( } 0 \text { least } \\
\text { effective - } 10 \text { most effective) }\end{array}$ & YES7- & YES- - & YES- 6 & YES- 7 & YES- 4 & YES- 3 & YES- 4 \\
\hline $\begin{array}{l}\text { Drinking and driving law and } \\
\text { its effectiveness score ( } 0 \text { least } \\
\text { effective - } 10 \text { most effective) }\end{array}$ & YES- 8 & YES- - & YES- 8 & YES- 8 & YES- 3 & YES- 4 & YES- 3 \\
\hline $\begin{array}{l}\text { Helmet law and its } \\
\text { effectiveness score ( } 0 \text { least } \\
\text { effective - } 10 \text { most effective) }\end{array}$ & YES- 5 & YES- - & YES- 8 & YES- 6 & YES- 3 & YES- 4 & YES- 2 \\
\hline $\begin{array}{l}\text { Seat belt law and its } \\
\text { effectiveness score ( } 0 \text { least } \\
\text { effective - } 10 \text { most effective) }\end{array}$ & YES- 7 & YES- - & YES- 8 & YES- 7 & YES- 2 & YES- 4 & YES- 3 \\
\hline $\begin{array}{l}\text { Child restraint law and its } \\
\text { effectiveness score ( } 0 \text { least } \\
\text { effective - } 10 \text { most effective) }\end{array}$ & $\mathrm{NO}$ & YES- - & YES- 7 & YES- 6 & YES- 3 & NO & $\mathrm{NO}$ \\
\hline $\begin{array}{l}\text { Mobile phone law and its } \\
\text { effectiveness score ( } 0 \text { least } \\
\text { effective - } 10 \text { most effective) }\end{array}$ & YES & YES & YES & YES & YES & YES & YES \\
\hline
\end{tabular}

prevention in Iran. In the pioneer countries there was a delegation to a particular organization, while in the other three countries a part of the Ministry of Transportation had the overall responsibility of RTIs. The results show that there is little evidence on the role and activities of the health systems in prevention of RTIs.

Various organizations with overlapping tasks are involved in RTIs prevention in Iran of which are the Ministry of Roads and Urban Development, Ministry of Industry, Mine and Trade, Ministry of Health and Medical Education, Traffic Police, Ministry of Culture and Islamic Guidance, Ministry of Education, The Legal Medicine Organization (forensic medicine), The Central Insurance Organization, Ministry of Justice, Ministry of 
Interior, Police, The Broadcasting Organization, and the Judicial Branch [50]. Each of these organizations has its own tasks and responsibilities but none of them has the sufficient authority and resources for integrated management of RTIs. Unlike this, in the countries which are successful in reducing the RTIs there is a particular organization that has the stewardship of the RTIs' prevention and the other involved organizations have to cooperate with it $[15,16]$. For example, in Canada the federal and provincial governments are responsible for road safety in their territory. The federal government has the commanding role and also gathers data and performs research to develop and evaluate the system. The police have executive role and develops the safety programs by the Judiciary [3]. In Iran, the study of Soori et al. proposed the Traffic Police or the President as the steward of the RTIs prevention. Although the Traffic Police have had significant role in management of RTIs and had impressive achievements in this regard, it does not have the sufficient authority and resources to be the steward. So it seems that, like many successful countries, a joint commission of stakeholder organizations with the chairmanship of the President and the clearly defined responsibilities and tasks could be better.

According to the findings of the study, a kind of delegation to a particular organization exists in the pioneer countries. It seems that delegation to a single organization might cause that organization to investigate the RTIs in a more specialized manner. Yet, the political support and the cooperation of other involved organizations must be assured. In case of developing countries that creating a separate organization for RTIs is hard or impossible, the alternative solution might be enforcing the road transportation unit of the Ministry. This enforcement can be as increasing the budget, increasing the authority, and providing political support. Finally, according to the experience of many countries, involvement and role playing of the government in control and prevention of RTIs seems inevitable [4, $6]$.

Results of the study showed that there is little evidence on the role and activities of the health systems in prevention of RTIs. Regarding the fact that the health system has to cure the people injured in RTIs, this sector should play a more active role in prevention of these accidents. Review of the literature showed that the role of the health system during and after the accident is well known but its role before the occurrence of the accident is neglected [44, 45, 51, 52]. One of the main roles that the health system had in most of the investigated countries is developing and implementing the care system. There are several experiences in health sector on developing the injury surveillance system of RTIs. An example of this task is the Road Traffic Injury Surveillance Project in India [44]. Another example is the RTIs surveillance in Pakistan which increased the focus on the RTIs
[46]. Experiences of the other countries also show that the health system can play an effective role in designing and implementing RTIs surveillance [47, 53-55]. A key point to consider is the cooperation of health system and the other involved sectors and organizations in design and implementation of such system. For, the RTIs had multilateral nature and need intra-sector efforts and integrated data.

Among the other roles that the health system has in the reviewed countries, is contribution and consultation with other stakeholders in developing the programs and policies of prevention of the RTIs. In any country, various organizations are involved in local, national, and international levels in the RTIs. But it should be kept in mind that the inter-sector collaboration would not be attained unless with political support and commitment of the macro-level policy makers of the country [56]. Another point to consider is the existence of a leading organization with defined tasks and sufficient resources; otherwise the inter-sector collaborations would face problems. Given the experiences of the reviewed countries and the structures of Iran, it is not suggested that the health system of the country play the leading role in the RTIs.

Findings of the study showed that the costs of the road traffic injuries (RTIs) in Iran are relatively high, compared to the pioneer countries and even to countries similar to Iran. The high economic and social costs of the RTIs are fundamental issues that challenge the policy makers of the countries[57, 58]. The economic costs of the RTIs include all costs made by the RTIs and the costs made due to the RTIs [59]. It is estimated that the global costs of the RTIs is 518 billion USD of which 65 billion USD belong to the low-and-middle income countries (LMICs). It is also estimated that the costs of the RTIs in low, middle, and high income countries equal to $1,1.5$, and 2 percent of the gross domestic product (GDP) of the country $[4,60]$. The cost of the RTIs in Iran was comprehensively assessed for the first time in the year 2001 to be 6170.7 billion Rials [61]. The study of Ainy et al., by using the willingness to pay (WTP) method, estimated that the costs of the RTIs in Iran equal to $6.46 \%$ of the country's GDP [62]. Yet, according to the research center of the Parliament (the Majlis), the economic and social costs of the RTIs in the country is as high as $8.5 \%$ of the GDP [63]. Anyway, results of the studies conducted in Iran show that the costs of the RTIs in Iran are high compared to other similar countries. Some possible reasons for this might be the lower safety of the roads in Iran which results in increased severity of the crashes, lower safety of the vehicles and their high price, younger age of the injured and dead victims, and the higher administrative costs in Iran. Thus it seems necessary to prevent the RTIs and to improve the safety of the roads and vehicles.

A limitation of this study was the access to the needed data because the required data were either 
managerial data or policy documents that were mainly in local languages. Thus we could not access and use those data.

In conclusion, results of the study suggest the existence of a particular organization as the steward of the RTIs prevention which should have sufficient authority and resources. In addition, more studies are recommended on the potential roles of the health systems in prevention of the RTIs.

Conflicts of Interest: None declared.

\section{References}

1. Zimmerman K, Jinadasa D, Maegga B, Guerrero A. Road traffic injury on rural roads in Tanzania: measuring the effectiveness of a road safety program. Traffic Inj Prev. 2015;16(5):456-60.

2. Krug EG, Organization WH. Injury: a leading cause of the global burden of disease. Geneva: World Health Organization; 1999.

3. Khorasani Zavareh D, Bohm $\mathrm{K}$, Khankeh $\mathrm{H}$, Talebian MT, Mohammadi R, Bigdeli $\mathrm{M}$, et al. Why should being visible on the road? A challenge to prevent road traffic injuries among pedestrians in Iran. $J$ Inj Violence Res. 2015;7(2):93-4.

4. Peden M, Scurfield R, Sleet D, Mohan D, Hyder AA, Jarawan E, et al. World report on road traffic injury prevention. World Health Organization Geneva; 2004.

5. Saber Azami-Aghdash, Homayoun Sadeghi-Bazarghani, Mahdiyeh Heydari, Ramin Rezapour, Derakhshani N. Economic Burden of Road Traffic Injuries in Iran: A Mini-systematic Review. J Clin Res Gov. 2016;5(2):1-6

6. Short MM, Mushquash CJ, Bédard M. Interventions for motor vehicle crashes among Indigenous communities: strategies to inform Canadian initiatives. Can J Public Health. 2014;105(4):e296-305.

7. Roy N, Murlidhar V, Chowdhury R, Patil SB, Supe PA, Vaishnav PD, et al. Where there are no emergency medical services-prehospital care for the injured in Mumbai, India. Prehosp Disaster Med. 2010;25(2):145-51.

8. Nantulya VM, Reich MR. The neglected epidemic: road traffic injuries in developing countries. $B M J$. 2002;324(7346):1139-41.

9. Krug E, Peden M, Mohan D, Hyder A, Norton R, Murray M. 5-year global strategy for road traffic injuries. Geneva: WHO; 2001.

10. Peden M. Global collaboration on road traffic injury prevention. Int J Inj Contr Saf Promot. 2005;12(2):85-91.

11. Azami-Aghdash S, Gorji HA, Shabaninejad H, Sadeghi-Bazargani H. Policy Analysis of Road Traffic Injury Prevention in Iran. Electron Physician. 2017;9(1):3630-3638.
12. Johnston BD. Road traffic injury prevention. BMJ Publishing Group Ltd; 2010.

13. Bhatti JA. Prioritisation of road traffic injury prevention fund spending in developing countries. Inj Prev. 2010;16(3):214-5.

14. Azami-Aghdash $S$, Najafzadeh MA, Heydari M, Rezapour R, Sajjadi Khasraghi J, Derakhshani N. ContentAnalysis of text and video news of traffic accidents in Iran during the years 2001-2017. J Clin Res Gov. 2018;7(1):1-6.

15. Stevenson M, Thompson J. On the road to prevention: road injury and health promotion. Health Promot $J$ Austr. 2014;25(1):4-7.

16. Al Turki YA. How can Saudi Arabia use the Decade of Action for Road Safety to catalyse road traffic injury prevention policy and interventions? Int $J$ Inj Contr Saf Promot. 2014;21(4):397-402.

17. Azami-Aghdash S, SadeghiBazarghani H, Heydari M, Rezapour R, Derakhshani N. Effectiveness of Interventions for Prevention of Road Traffic Injuries in Iran and Some Methodological Issues: A Systematic Review. Bull Emerg Trauma. 2018;6(2):90-99.

18. National policy framework on injury prevention in Srilanka. Ministry of health, nutrition and welfare; 2003. p. 5-14.

19. Norman LG, Organization WH. Road traffic accidents: epidemiology, control, and prevention. 1962.

20. Ghaffar A, Hyder AA, Masud TI. The burden of road traffic injuries in developing countries: the 1st national injury survey of Pakistan. Public Health. 2004;118(3):211-7.

21. Speziale HS, Streubert HJ, Carpenter DR. Qualitative research in nursing: Advancing the humanistic imperative: Lippincott Williams \& Wilkins; 2011.

22. Grbich C. Qualitative data analysis: An introduction: Sage; 2012.

23. Pope C, Ziebland S, Mays N. Qualitative research in health care. Analysing qualitative data. BMJ. 2000;320(7227):114-6.

24. Hsieh HF, Shannon SE. Three approaches to qualitative content analysis. Qual Health Res. 2005;15(9):1277-88.

25. Reichenbach M. Vision Zero. Springer; 2011.

26. In: Iran Road Maintenance and Transportation Organization. 2016 [Available from: http://www.rmto.ir/.

27. In: Ministry of Shipping,Government of India. Organisational History. [Accessed: 5 October 2014]. Available from: https://en.wikipedia.org/wiki/ Ministry of Shipping (India).

28. Peden M, Scurfield R, Sleet $D$, Mohan D, Hyder AA, Jarawan E, et al. World report on road traffic injury prevention. World Health Organization: Geneva; 2004.

29. In: Ministry of Road Transport and Highways, Government of India Wings under Ministry, MORTH. [Accessed: 5 October 2014]. Available from: http://indiastandardsportal. org/standardbodiecontent. aspx?StandardBodyId=14.

30. Kahn CA. National Highway Traffic Safety Administration (NHTSA) Notes. Results of the 2013-2014 National Roadside Survey of Alcohol and Drug Use by Drivers. Ann Emerg Med. 2015;66(6):669.

31. Sleet DA, Dinh-Zarr TB, Dellinger AM. Traffic safety in the context of public health and medicine. Improving Traffic Safety Culture in the United States. 2007:41.

32. P People H, Health UDo, Services H. Healthy people 2010: Office of Disease Prevention and Health Promotion, US Department of Health ...; 2000.

33. $P$ ealth E-UDo, services $h$, Control CfD, Prevention, Statistics NCfH. Healthy people 2010: Final review: US Government Printing Office; 2012.

34. In: Wikipedia contributors. General Directorate of Highways (Turkey). Wikipedia, The Free Encyclopedia. [Accessed: July 24, 2016] Available from: https://en.wikipedia. org $/$ w/index.php?title $=$ General Directorate_of_Highways (Turkey)\&oldid $=724691292$.

35. Belin $\mathrm{M} \AA$, Tillgren $\mathrm{P}$, Vedung $\mathrm{E}$. Vision Zero--a road safety policy innovation. Int J Inj Contr Saf Promot. 2012;19(2):171-9.

36. Fahlquist JN. Responsibility 
ascriptions and Vision Zero. Accid Anal Prev. 2006;38(6):1113-8.

37. Organization WH. Developing policies to prevent injuries and violence: guidelines for policy-makers and planners: Geneva: World Health Organization; 2006.

38. Bergh $T$, Carlsson A, Larsson $M$. Swedish vision zero experience. International journal of crashworthiness. 2003;8(2):159-67.

39. Al Turki YA. How can Saudi Arabia use the Decade of Action for Road Safety to catalyse road traffic injury prevention policy and interventions? Int $J$ Inj Contr Saf Promot. 2014;21(4):397-402.

40. Road safety: The critical transportation issue in Canada. Overview. Annual report on road safety vision. 2010: 2002.

41. Johnston I, Campbell B, Mohan D, Tiwari G, Petrucelli E, Mackay G, et al. Reflections on the transfer of traffic safety knowledge to motorising nations; 1998.

42. Aeron-Thomas A. A Review of Road Safety Management and Practice. Final Report. Crowthorne, England: Transport Research Laboratory and Babtie Ross Silcock; 2002. TRL Report PR/INT216; 2002.

43. Gopalakrishnan S. A public health perspective of road traffic accidents. J Family Med Prim Care. 2012;1(2):144-50.

44. Bao J, Bhalla K, Bennett S. Evidence to inform intersectoral policies: a comparison of health and transport sector evidence in support of road traffic injury prevention. Health Res Policy Syst. 2015;25;13:19.

45. Slesak $\mathrm{G}$, Inthalath $\mathrm{S}$, Wilder-Smith A, Barennes H. Road traffic injuries in northern Laos: trends and risk factors of an underreported public health problem. Trop Med Int Health. 2015;20(11):1578-1587.

46. Razzak JA, Shamim MS, Mehmood A, Hussain SA, Ali MS, Jooma R. A successful model of Road Traffic Injury surveillance in a developing country: process and lessons learnt. BMC Public Health. 2012;12:357.

47. Ma S, Li Q, Zhou M, Duan L, Bishai D. Road traffic injury in China: a review of national data sources. Traffic Inj Prev. 2012;13 Suppl 1:57-63.

48. Puvanachandra P, Hoe C, Ozkan T, Lajunen T. Burden of road traffic injuries in Turkey. Traffic Inj Prev. 2012;13 Suppl 1:64-75.

49. Organization WH. Global status report on road safety 2015: World Health Organization; 2015.

50. Soori H, Movahedinejad A, Mahfozphoor S, Movahedi M, Rezazadeh Azari M, Hatamabadi H, et al. A Practical Model of Political Mapping in Road Traffic Injury in Iran in 2008. Hakim. 2009;12(3):1-9.

51. Organization WH. WHO calls for stronger focus on adolescent health. WHO Media centre. 2014.

52. Chini F, Farchi S, Camilloni L, Giarrizzo ML, Giorgi Rossi P. Health care costs and functional outcomes of road traffic injuries in the Lazio region of Italy. Int J Inj Contr Saf Promot. 2016;23(2):145-54.

53. Ward E, McCartney $\mathrm{T}$, Arscott-Mills S, Gordon N, Grant A, McDonald $\mathrm{AH}$, et al. The Jamaica Injury Surveillance System: a profile of the intentional and unintentional injuries in Jamaican hospitals. West Indian Med J. 2010;59(1):7-13.

54. Rojas Medina Y, Espitia-Hardeman V, Dellinger AM, Loayza M, Leiva $\mathrm{R}$, Cisneros G. A road traffic injury surveillance system using combined data sources in Peru. Rev Panam Salud Publica. 2011;29(3):191-7.

55. Hatamabadi HR, Vafaee R, Haddadi M, Abdalvand A, Soori H. Necessity of an integrated road traffic injuries surveillance system: a communitybased study. Traffic Inj Prev. 2011;12(4):358-62.

56. Menon GR, Gururaj G, Tambe M, Shah B. A multi-sectoral approach to capture information on road traffic injuries. Indian journal of community medicine: official publication of Indian. Association of Preventive \& Social Medicine. 2010;35(2):305.

57. Olukoga A. Cost analysis of road traffic crashes in South Africa. Inj Control Saf Promot. 2004;11(1):59-62.

58. Pérez-Núñez R, Pelcastre-Villafuerte B, Híjar M, Avila-Burgos L, Celis A. A qualitative approach to the intangible cost of road traffic injuries. Int J Inj Contr Saf Promot. 2012;19(1):69-79.

59. Elvik R, Amundsen AH. Improving road safety in Sweden. TØI report. 2000;490:2000.

60. Mohan D. Traffic Injuries and Fatalities in India. Transportation Research \& Injury Prevention Programme, Indian Institute of Technology Delhi; 2004.

61. Ayati E. The cost of road accidents in Iran. International Journal of Engineering. 2006;2(3\&4):98-103.

62. Ainy E, Soori H, Ganjali M, Le H, Baghfalaki T. Estimating cost of road traffic injuries in Iran using willingness to pay (WTP) method. PLoS One. 2014;9(12):e112721.

63. In: Center: MR. The cost of road accidents is equivalent to 8.5 percent of GDP 2014.[Accessed: 2014]. Available from: http://www.farsnews.com/ newstext.php?nn=13920814001372.

\section{Open Access License}

All articles published by Bulletin of Emergency And Trauma are fully open access: immediately freely available to read, download and share. Bulletin of Emergency And Trauma articles are published under a Creative Commons license (CC-BY-NC). 